\title{
UN VICO PERSONAL
}

\section{Francisco J. Navarro Gómez (Centro de Investigaciones sobre Vico)}

RESUMEN: Reseñamos a continuación las líneas conceptuales del pensamiento viquiano que, dentro de su obra latina, entendemos como más conspicuas globalmente consideradas y de mayor influjo en nosotros.

Palabras ClaVe: Vico, $350^{\circ}$ Aniversario, Filología, Derecho, Filosofía jurídica, verosímil, naturaleza humana, F.J. Navarro Gómez.

\section{A personal Vico}

ABSTRACT: We outline below the conceptual lines of Viquian thought that, within his Latin work, we consider the more conspicuous ones, globally considered, and have had a greater influence on us.

KeYwords: Vico, 350 th Anniversary, Philology, Law, Legal Philosophy, plausibility, human nature, F.J. Navarro Gómez.

\section{Un Vico personale}

RIASSUNTO: Esponiamo qui di seguito le linee concettuali del pensiero vichiano che, all'interno della sua opera latina, crediamo le più cospicue, globalmente considerate, e di maggiore influenza sulla nostra riflessione.

Parole chiave: Vico, $350^{\circ}$ Anniversario, Filologia, Diritto, Filosofia giuridica, verosimile, natura umana, F.J. Navarro Gómez.

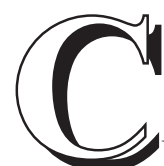

uando, hace ya más de veinticinco años, recibí la invitación del prof. Miguel A. Pastor, secretario del Centro de Investigaciones sobre Vico -actuando en nombre propio y en el de su director, el prof. J.M. Sevilla-, a hacerme cargo de la translación al español de parte de la obra latina de Vico (inicialmente las Orationes inaugurales y luego, sucesivamente, De mente heroica, De nostri temporis studiorum ratione y De antiquissima Italorum sapientia), para que formase parte de una sección, la "Biblioteca", integrada en los Cuadernos sobre Vico, revista de periodicidad anual que dicho Centro contribuía a editar, la aceptación de la propuesta apenas me suscitó duda alguna, una vez practicadas las oportunas indagaciones acerca

Este artículo responde a una invitación expresa por parte de la Dirección de la Revista para este volumen especial por el $350^{\circ}$ Aniversario del nacimiento de G. Vico, habiendo superado los criterios de valoración y del proceso de aceptación. 
de la generalidad de la labor de dicho autor, que conocía básicamente a través de la Scienza nuova y de algunos otros trabajos como los dos últimos anteriormente aludidos. Y tampoco se me planteó objeción o indecisión cuando, pocos años más tarde, los profesores José M. Sevilla y Emilio Hidalgo-Serna me propusieron que acometiese asimismo la edición, traducción y anotación comentada del conjunto de la obra latina viquiana, dentro de su proyecto de publicación de diversos estudios humanísticos a través de la editorial Anthropos -y más concretamente de su colección Autores, Textos y Temas. Humanismo, que ambos dirigen- y en colaboración con la Stiftung Studia Humanitatis, presidida por este último. Fruto de este acuerdo han visto ya la luz las Obras. Oraciones inaugurales \& La antiquísima sabiduría de los italianos [2002] (donde se incluyen -como oraciones inaugurales tambiénDel método de estudios de nuestro tiempo y Sobre la mente heroica), Obras II. Retórica (Instituciones de Oratoria) [2004], Obras III. El Derecho Universal [2009] y Obras IV. Reivindicaciones de Vico y otros escritos latinos [2016]. Y es prácticamente inmediata ya la edición de las Obras V. Escritos históricos: Gestas de Antonio Carafa y La Conspiración Partenopea (La Conspiración de los Príncipes Napolitanos). Y en otro orden de cosas y para continuar con mis trabajos viquianos, desde la comunicación -centrada en la tópica viquiana en relación con el De Officiis de Cicerón- al Congreso celebrado en Sevilla [1999] Pensar para el nuevo siglo. Giambattista Vico y la cultura europea, mis numerosos artículos aparecidos durante estos años en Cuadernos sobre Vico, así como en el Bollettino del Centro di studi vichiani y, últimamente, en la revista italiana Rocinante, han supuesto mayoritariamente un esfuerzo por referenciar la filología a la filosofía, excepción hecha de algunos otros concernientes a determinados aspectos de la filosofía jurídica y política en relación con Vico.

Pues bien, la razón de aquella susodicha ausencia de indeterminación no es única, sino plural. Para empezar, y sin entrar aún en los contenidos, por la propia forma que los recoge, esto es, lo que motivó precisamente que se recabase nuestra colaboración, la lengua que los moldea: el que aquellos vengan redactados originalmente en latín siempre supone a nuestros ojos un plus de interés y un aliciente añadido. De hecho, ya años antes había ensayado por propia iniciativa la traducción de autores como el Erasmus Roterdamensis del De duplici copia o el Athanasius Kircher de la Turris Babel y del Arca Noë. Es decir, había cabalgado en una secuencia temporal entre los ss. XV-XVI primero y mediados del XVII a continuación, para pasar a transitar ahora entre finales del XVII y primera mitad del XVIII (a la muerte de Kircher, Vico contaba escasamente doce años). Un aspecto este de la lengua en que los postulados de Vico no diferían mucho de los de Pascal -nacido casi medio siglo antes-, cuyo padre, viudo y por ende encargado de su educación, mostraba ciertas reticencias a que este, muy dotado para las matemáticas y la física, descuidase por ello su formación en latín y griego; mientras que Vico continúa afirman- 
do el carácter internacional del latín -al que en ocasiones transforma casi en lengua franca-, según nos dice en el "Proemio", in fine, a las Gestas de Antonio Carafa:

«Escribo en latín: pues las gestas grandes y dignas de inmortal memoria merecen ser confiadas a la lengua en que habló la majestad romana, y que se espera que, junto con las leyes y ceremonias romanas, durará eternamente: y ésta es la razón cierta de que se narre sobre un personaje renombrado entre muchas y variadas naciones de Europa en la lengua común a todas ellas»,

buscando así una garantía de permanencia, de perpetuidad incluso, capaz de hacer bueno el verso horaciano "Exegi monumentum aere perennius". ${ }^{1}$

Mas fue una de las razones de mi aceptación (nunca advertida hasta este momento, en que la reflexión sobre el hecho me hace reparar en ello) la sensación de cercanía, de afinidad -más que a la labor de Vico, que, aunque inestimable, conocía hasta ese momento, como acabo de señalar, solo a través de lo que podríamos denominar "algunas obras mayores"- con sus inclinaciones profesionales y académicas, con aquellas características que constituían su triple (¿cuádruple?) vertiente vocacional y/o formativa, coincidentes, por otra parte, con las de mi admirado Cicerón y con las mías propias, a saber: la filosófica, la jurídica y la filológica, con la dicotomía de esta última a su vez en filológica stricto sensu (en la que incluiríamos la oratoria) y lato sensu (historia), parafraseando al citado Erasmo del De duplici copia verborum ac rerum. Hubo de ser así, habida cuenta de que el diseño editorial consustancial al plan elaborado por los Cuadernos sobre Vico confluía con mis propios intereses e inquietudes, unas inclinaciones estas que hicieron que, andando el tiempo, mi tesis doctoral en filosofía versase sobre el "derecho natural de gentes" y, más concretamente, consistiese en la traducción del latín al español del Derecho Universal de G. Vico, anotado y comentado, y, paralelamente, en la investigación, redacción y posterior publicación de una monografía sobre el mismo titulada La razón de la ley. Un estudio, confrontación histórica y filosófica sobre El Derecho Universal de G. Vico. ${ }^{2}$

No pude por menos, pues, que sentirme tentado por el reto que se me planteaba, pues, como decía el profesor J.M. Sevilla -que, con agudeza, supo ver tal atracción antes que yo mismo- en su aludida Presentación:

«[...] Licenciado en clásicas, profesor de Latín y doctor en Filosofía.

Con estas condiciones no sabremos a ciencia cierta si él fue llamado

1. Horacio, Carmina, III, 30, 1.

2. F.J. NAVARro Gómez, La razón de la ley. Un estudio, confrontación histórica y filosófica sobre El Derecho Universal de G. Vico, pres. por José M. Sevilla, Fénix Editora, Sevilla, 2009. 
por Vico, o a la inversa. Lo importante es que la llamada viene siendo constante y coherentemente [cor] respondida». ${ }^{3}$

Grande es por mi parte, pues, la deuda contraída con Vico respecto de las tres vertientes epistémicas anteriormente apuntadas, en ocasiones como causa -o al menos como pretexto- y en otras como obligación conceptual, si bien el débito, lejos de ser exclusivamente personal, será con la mayor frecuencia compartido con todo lector que se acerque a su obra. Así, e. g., en lo que toca al aspecto filológico propiamente dicho, y concretamente a la retórica, el estudio de las Institutiones Oratoriae me ofreció la oportunidad de, amén de algunas pinceladas acerca de la oratoria profana y sacra contemporáneas, refrescar, revisar y completar casi exhaustivamente la retórica clásica buscando en ella sus fuentes últimas, y de constatar que, como rétor, bebe en las de Cicerón y Quintiliano tanto en las fórmulas doctrinales como en la secuencia del período oratorio, mientras que en su materialización práctica se reflejan los influjos de Tácito y de los cómicos latinos. Asimismo, hemos tenido la ocasión -algo que no siempre ocurre, pues en contadas ocasiones los rétores asumen también ellos mismos la función de oradores- de contrastar sus postulados teóricos con la plasmación práctica de éstos, y de observar su coherencia interna en los diversos panegíricos, oraciones inaugurales, laudatio funebris, etc., nacidos de su mente y sus manos, constatando así su maestría en el uso de la estructura trimembre, la alternancia del quiasmo y el paralelismo o, intelectualmente, del argumento a fortiori. Puede, paralelamente, rastrearse en sus discursos el ascendiente de los diálogos platónicos en el modo de arrastrar al lector al punto conclusivo al que se le quería llevar ab initio y en función del cual se va construyendo y desplegando el argumento, quod erat demonstrandum. Y, para poner fin al presente plano, la translación de esta obra, así como del resto de su producción en latín, me ha permitido poner en práctica mis propias reflexiones y posiciones, acumuladas durante tantos años, sobre la traducción en general y sobre la de Vico en particular, en quien -en su condición de rétor- tan fundidas se encuentran filosofía y filología, no siendo, pues, en él -como en tantas ocasiones hemos propugnado- la del respeto al estilo una cuestión baladí.

Y en la otra cara dicotómica de la filología tomada lato sensu, esto es, la historia -haciendo aquí abstracción de la primera, aunque en ella verba y res se hallan, más que nunca, (con)fundidas-, debemos también a Vico una visión bien fundada y documentalmente justificada de un amplio período de la guerra del Sacro Imperio contra el turco para la recuperación de Hungría y Transilvania (las Gestas de Antonio Carafa), así como de un episodio transcendental de la historia de

3. Ibíd., p. IX. Palabras estas que ya hemos tenido ocasión de citar anteriormente, v. g., en el trabajo con que contribuimos al último número de la revista italiana Rocinante (en impr.). 
Nápoles desde la más inmediata de las cercanías, tanto local como temporal ( $L a$ Conspiración Partenopea o La Conspiración de los Príncipes Napolitanos), cuyos textos me permitirán, en ambos casos y mediados por las reflexiones que en mí han suscitado durante el proceso de traducción, nuevos futuros estudios y trabajos a ellos vinculados.

De otro lado, conceptualmente, existe siempre en Vico una latente -cuando no manifiestamente expresa- intención de superación, de composición, de conciliación e incluso de integración a veces de elementos antagónicos, discursivamente bifrontes o jánicos, como pueden ser los de verum/factum y verum/certum, y, en relación con ellos, verum/verisimile // razón/autoridad y necesidad/voluntad // filosofía/filología y teoría/praxis, divino/humano... De entre todos ellos -que vienen a reflejar el contraste, la pugna entre lo genérico, universal y absoluto frente a lo específico, particular y concreto, cuya adaptación o adecuación en derecho se ejemplifica siguiendo el modelo de uso de la regula plumbea Lesbia de que hablaba Aristóteles- es para mí, sin lugar a dudas, la noción de verosimilitud y la transcendencia a ella asignada, derivada en gran medida de la primera oposición señalada supra, la que mayor fortuna ha tenido en buena parte del pensamiento filosófico viquiano, y con una repercusión inmediata en el despliegue de su teoría retórica y jurídica, así como (junto con algunos otros extremos de los que inmediatamente pasaremos a dar cuenta) en el mío propio y en las líneas de desarrollo de mi razonamiento y mi labor de los últimos veinte años: ${ }^{4}$ esa misma verosimilitud que está en la base, no ya del pensar, sino incluso del sentir general, y que hacía que la última etapa y la más excelente de la formación del ciudadano romano se volcase en la oratoria, ya fuese este a consagrarse a la vida pública o al ejercicio del derecho, al discurso político o al forense, que en la verosimilitud precisamente tienen, ambos, su asiento.

Centrándonos por último, pues, en el ascendiente que sobre nosotros tiene su pensamiento filosófico, y más concretamente el de su filosofía jurídica, por el que más concernidos nos sentimos, es precisamente ese criterio de verosimilitud -y no el de verdad- el hilo conductor que está en la base de múltiples hallazgos viquianos. El hombre, de una naturaleza ya no íntegra, sino corrupta (lapsa) tras la caída, se ve imposibilitado para conocer el «modo en que la cosa se hace», el noscere per caussas, para un conocimiento pleno y no limitado del verum, ya que solo puede conocer con verdad aquello que él mismo ha creado, único lugar en que verum ipsum factum, esto es, donde verum et factum convertuntur: ${ }^{5}$ la aritmética, la geometría ${ }^{6}$ (nue-

4. Vid., v. g., Francisco J. NavarRo Gómez, «Discurso lógico y discurso retórico: historia de un problema, ¿o problema de una historia?», Cuadernos sobre Vico, $\mathrm{n}^{\circ}$ 15-16, 2003, pp. 121-150.

5. La antiquísima sabiduría de los italianos, en G. VICO, Obras. Oraciones inaugurales \& La antiquísima sabiduría de los italianos, pres. Emilio Hidalgo-Serna, intr. José M. Sevilla, ed., trad. del latín y notas Francisco J. NAVArRo Gómez, Anthropos, Barcelona, 2002, p. 133.

6. Ibíd., pp. 150-151. 
vos mundos con sus propias leyes internas que contribuyen a adecuar "el mundo" a las limitaciones de la mente humana y donde, en realidad, no hay identificación sino representación, pues el número no es el sonido, como ya puntualizó acertadamente Marin Mersenne) y parcialmente su propia historia, de la que es autor, aunque no así de su misma naturaleza que la forja; con ciertos ecos que rastrearemos en Ortega, su naturaleza consiste precisamente en ser histórico, pues en el estado de natura lapsa finaliza su ser puro e incontaminado y comienza su devenir, su proceso de cambio: y así, por ende, no pudiendo acceder al verum, ha de contentarse con lo verisimile, con esa asimilación a la verdad que «en la mayor parte de las ocasiones es verdadero, y raramente falso». ${ }^{7}$ Este verosímil, que tanto contribuyó a su doctrina político-jurídica, no es, en efecto, la verdad, ni siquiera una verdad meramente formal o la verdad material procesal o judicial, pero sí es la verdad en la que la generalidad consiente, «la verdad que así parece», ${ }^{8}$ pues «de lo verosímil se engendra el sentido común».9

Y de otro lado, y junto a logros tales como el reconocimiento en algún pasaje del Derecho Universal de una suerte de derecho de resistencia (frente a la irreversibilidad del pactum subiectionis sostenida por Hobbes, entre otros muchos) -si bien negado previamente, v. g., en las Gestas de Antonio Carafa- en caso de no cumplirse las condiciones por las que con su subscripción se transmitió la soberanía, lo que constituye, además, todo un precedente, supone probablemente el mayor acierto el haber partido, para la construcción de su edificio teórico-conceptual, de la previamente aludida naturaleza humana en su doble faceta pasionalracional: «Concluí finalmente, pues, que los principios de la jurisprudencia deben deducirse, no de los escritos o las palabras de los paganos, sino del verdadero conocimiento de la naturaleza humana, que ha nacido del verdadero Dios». ${ }^{10}$ Ello le permitió conquistas tales como el poder sostener fundadamente que el común derecho natural de gentes, esto es, el derecho histórico de los procesos civiles, y las similitudes en el tránsito del derecho de gentes mayores a las menores no se explican por la comunicación de tal derecho, sino que, sentada la incomunicabilidad del mismo, dichas consonancias entre derechos resultan de la común naturaleza humana de sus forjadores; o el haber logrado escapar del ahistórico, estricto e inmutable derecho natural de los filósofos, cimentado solo en la razón; o el haber establecido la historicidad de tal derecho basándose en la «naturaleza humana, porque, debido al libre albedrío, es muy incierta»;11 o el haber propugnado que, por

7. Del método de estudios de nuestro tiempo, ibíd., p. 82.

8. Ibíd., p. 95.

9. Ibíd., p. 82.

10. G. Vico, Obras III. El Derecho Universal, pres. Emilio Hidalgo-Serna y José M. Sevilla, ed., intr., trad. del latín y notas de Francisco J. Navarro GómeZ, Anthropos, Barcelona, 2009, «Proloquio», «Inicio de la obra», in fine, § 24, p. 12.

11. Del método de estudios de nuestro tiempo, en G. VIco, Obras. Oraciones inaugurales [...], op. cit., p. 93. 
una pulsión ingénita en tal naturaleza, la historia, la evolución del derecho es un proceso tendente desde el caos y la anomia inicial tras la caída, a la ley de la fuerza, pasando luego por el derecho estricto («summum ius, summa iniuria», según reza el proverbio recogido en Cicerón $)^{12}$ hacia un cada vez más acabado derecho equitativo y, en él, de la equidad natural a la civil, a un mayor amoldamiento del ius quia iussum al ius quia iustum.

Así, para Vico, mientras que -excúsesenos la autocita-

«el derecho natural basado en la razón sería prácticamente estable y aprocesual (cayendo con ello en el anacronismo resultante del hecho de partir de una razón ahistóricamente considerada y dando así lugar al por él censurado "derecho natural de los filósofos", anacrónico por no ajustarse al hecho de que "le dottrine debbono cominciare da quando cominciano le materie, che trattano"), ${ }^{13} \mathrm{el}$ derecho natural de gentes reivindicado por Vico es un derecho nacido de la filosofía profunda o, lo que es lo mismo, del conocimiento de la naturaleza humana, histórico ${ }^{14} \mathrm{y}$, por ende, contaminado de realidad y mezclado -frente al "puro" de los filósofos- de derecho positivo, ${ }^{15}$ cuya parcial, paulatina e inercial mutabilidad ${ }^{16}[\ldots]$ no siendo exactamente el mismo el hombre de los orígenes nacido de los bestioni y el hombre de la razón desplegada, le viene de la evolución del sujeto en el que se asienta: la naturaleza humana». ${ }^{17}$

Lo contrario, la imposición de una absoluta inmutabilidad del derecho natural, es lo que, llevado al extremo, justifica el «etiamsi daremus [...] non esse Deum» de Grocio. ${ }^{18}$ El establecimiento de un derecho natural humano (no divino, no eterno), haciendo abstracción de una historia basada en la naturaleza común a todos ellos en la que necesariamente habría de fundarse - ¿"natural" de qué, si no?-, equivale a intentar construir la historia de los hombres individuales, de sus comportamientos y modos de actuación, y obtener las pautas que de ahí pudiesen derivarse sin contar con sus respectivos caracteres, índoles y, en definitiva, naturalezas. Lo permanente, inmutable, eterno, no sería la base literal o material de tal derecho,

12. De officiis, I, 33 .

13. SN44, degnità CVI $\S 314$.

14. Ya que, históricamente, no existe un único derecho de gentes, sino que se da en él una evolución temporal. Vid., v. g., De Constantia, II, caps. XX § 37 y XXII § 24, en G. VICO, Obras III. El Derecho Universal, op. cit.

15. Cfr. De Uno, cap. CXXXVI § 3, ibídem.

16. Incluso cuando alude a la "inmutabilidad" o "rigor" del derecho natural [no del de gentes], lo hace más a la característica y esencial forma de operar el posterius sobre el prius que al contenido del derecho natural en sí, de forma análoga a lo que ocurre entre la razón y el espíritu de la ley, lo que le permite el aserto, con San Agustín, de que «Dios protege nuestra libertad de arbitrio con su inmutable decreto» (De Uno, cap. LXXX, ibíd.).

17. Ibíd., «Introducción», p. XXXI.

18. H. Grocio, De iure belli ac pacis, Prolegomena § 11. 
sino sus principios informadores, lo que podría no ya permitir, sino incluso imponer tales transformaciones en el derecho natural de gentes, de forma acorde a la naturaleza histórica del hombre y a «le modificazioni della nostra medesima Mente Umana». ${ }^{19}$ Pues en caso contrario nos hallaríamos, como intentaba exponer en la monografía antes aludida, no ante "la razón de la ley", sino ante "la ley de la razón".

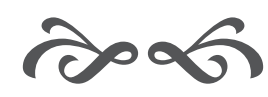

19. $S N 44, \S 331$. 